\title{
Evaluation of Skin Response After Erbium:Yttrium- Aluminum-Garnet Laser Irradiation: A Network Analysis Approach
}

\author{
Majid Rezaei-Tavirani', Mostafa Rezaei Tavirani ${ }^{2}$, Mona Zamanian Azodi ${ }^{3}$, Hamideh Moravvej Farshi ${ }^{4}$, \\ Mohammadreza Razzaghi ${ }^{5}$ \\ ${ }^{1}$ Faculty of Medicine, Iran University of Medical Sciences, Tehran, Iran \\ ${ }^{2}$ Proteomics Research Center, Faculty of Paramedical Sciences, Shahid Beheshti University of Medical Sciences, Tehran, \\ Iran \\ ${ }^{3}$ Proteomics Research Center, Shahid Beheshti University of Medical Sciences, Tehran, Iran \\ ${ }^{4}$ Skin Research Center, Shahid Beheshti University of Medical Sciences, Tehran, Iran \\ ${ }^{5}$ Laser Application in Medical Sciences Research Center, Shahid Beheshti University of Medical Sciences, Tehran, Iran
}

\section{*Correspondence to \\ Mona Zamanian Azodi, Proteomics Research Center (PRC), Darband St., Qods Sq., Tehran, Iran. \\ Tel:+982122714248; \\ Email:mona.azodi@gmail.com}

Published online July 6, 2019

\begin{abstract}
Introduction: Application of laser in medicine and cosmetic purposes has raised grossly in recent years. There are contradictory finding about its side effects. In this research critical differentially expressed proteins after irradiation erbium:yttrium-aluminum-garnet (Er:YAG) laser on skin are investigated.

Methods: Proteome data including 31 proteins were obtained from a proteomics investigation of laser irradiation, Er:YAG on female mouse skin that are published by Pan et al. The query proteins and 100 related ones were included in the protein-protein interaction (PPI) network. The central nodes were determined and all of nodes were included in action maps. Expression, activation, inhibition, binding, and reaction were considered in action plan.

Results: Numbers of 16 proteins were recognized by STRING database and were included in the network. Except PHRF1, the other 15 query proteins were included in the main connected component of the constructed network. Ten central nodes of the network and ten numbers of top query proteins based on degree value were identified as central proteins of the network. All nodes of the network analyzed via action maps and the important acted nodes were determined as RPSA, GAPDH, TPT1, DCTN2, HSPB1, and PDIA3.

Conclusion; Two balanced processes including cancer promotion and cancer prevention were after irradiation were identified.

Keywords: Laser irradiation; Erbium:yttrium-aluminum-garnet (Er:YAG); Skin care; Proteomics; Protein-protein interaction network analysis; Biological process.
\end{abstract}

\section{Introduction}

Laser therapy is widely applied for skin care and treatments. It is useful for skin problems such as facial skin damage therapy caused mostly by sunburn, acne, and aging. ${ }^{1}$ It accounts for safe substitute for other kinds of therapies with less complications if using properly, it is also applied with a growing rate. However, as mentioned if not applied wisely, there could be some side effects including excessive pigmentation in skin, skin redness, atrophic scars, infections, acne outburst, skin itchiness, and eczema. ${ }^{2}$ One of the methods is the erbium:yttriumaluminum-garnet (Er:YAG) that could be used for surgical resurfacing. ${ }^{2}$ Molecular studies, on the other hand, showed promising in terms of detecting associated biomarkers of the therapeutic agents' mechanisms of action in human body. ${ }^{3}$ One of the important aspects of usage each therapeutic elements is their possible side effects besides their benefits. In view of this fact, it is important to explore these features of any applied methods and medicine via molecular approaches especially the high-throughput techniques. ${ }^{4}$ The famous research studies in this field include proteomics, genomics, and metabolomics. Proteomics as one of the potential approaches that can detect hundreds of proteins in an investigating sample of interest is in great attention. ${ }^{5}$ It is known that proteins are the functional parts of molecular processes and ultimately could be screened by proteomics. ${ }^{6}$ In addition to proteomics, complementary studies such

Please cite this article as follows: Rezaei-Tavirani M, Rezaei Tavirani M, Zamanian Azodi M, Moravvej Farshi H, Razzaghi M. Evaluation of skin response after erbium:yttrium-aluminum-garnet laser irradiation: a network analysis approach. J Lasers Med Sci. 2019;10(3):194199. doi:10.15171/jlms.2019.31. 
as bioinformatics could add more essential information to the proteomics data. The identified differentially expressed proteins of specific condition, could be more dig in by evaluating their prominent roles in relation to other molecules specifically proteins. Analyzing proteinprotein interaction (PPI) network is one of the ways in this regard that offers important notions. ${ }^{7}$ Differentially expressed proteins that are in condense interactions (central proteins) with other proteins could be more vital than the other ones. Consequently, identifying these central differentially expressed proteins worth a lot. ${ }^{8}$ In this sense, here is tired to recognize the laser-skin interactions through PPI network analysis of proteome profile. In other words, this in silico investigation aims to better understand the skin recovery processes from Er:YAG treatment and its safeness.

\section{Materials and Methods}

In this study, the proteome data is obtained from a proteomics investigation of laser irradiation, Er:YAG on female mouse skin. The mouse model was (ICR-Foxn1nu strain, 8 weeks old) and the conducted study by Pan et al was entitled "Systematic evaluations of skin damage irradiated by an erbium: YAG laser: Histopathologic analysis, proteomic profiles, and cellular response". ${ }^{2}$ Biopsies, 250 mg was applied from 4, 24 and $96 \mathrm{~h}$ laser exposure tissues for the 2D-electorphorsis- MALDI-TOF-TOF MS based proteomics. A number of 31 proteins that were recognized by the main research were chosen for the bioinformatics analysis in here. Cytoscape 6.3.0 (https://cytoscape.org/) ${ }^{9}$ and its plug-ins performed the PPI network analysis of these queried proteins. The network construction was by the use of STRING DB (https://string-db.org/), available in Cytoscape platform. STRING software applies four sources to retrieve data including protein query, PubMed Query, Disease Query, and protein/compound query .${ }^{10,11}$ A number of 100 neighbor nodes were designated for the network construction in this study. In a way that they were added to the main query proteins with the confidence score cut off of 0.4 as the default option. Next step was to analysis the central elements of this constructed network via Network Analyzer. ${ }^{12}$ The focus was on two important centrality parameters including degree $(\mathrm{K})$ and betweenness centrality $(\mathrm{BC})$ for the whole network and also between queried proteins. Nodes with high amount of these two parameters are called hubbottlenecks. Hubs are vertices with high degrees while bottlenecks are nodes with high amounts of influence over the information passing on a path between other nodes. Action type analysis was handled for the whole resulted network and high interacting nodes by CluePedia panel. ${ }^{13}$ This application could analysis interactions expression, activation, inhibition, post-translational modifications, and catalysis. Here, we chose expression, inhibition, and activation patterns for our study as individual networks. The statistical methods for this analysis was by the use of Kappa scoring (0-1) for edge strength scaling, which is shown by thickness. ${ }^{14}$

\section{Results}

Numbers of 31 proteins (Table 1) were included in the PPI network. Among 31 query proteins, 16 individuals were recognized by STRING database. The network including 16 recognized query proteins and 100 related ones was constructed by Cytoscape software (Figure 1). The network was included one isolated protein and a main connected component including 115 nodes. PHRF1 is a recognized gene by STRING and is not included in the network (Figure 1). As depicted in the Figures 2-4, action maps including expression, activation, and inhibition were constructed for the 116 overall nodes. Binding and reaction related to the 116 nodes are shown in Figure 5. As it is illustrated in the Figure 5 the query proteins have heterogeneous binding pattern with the other proteins. It

Table 1. Numbers of 31 significant differentially expressed proteins (DEPs) related to skin of female nude mouse exposed to Er:YAG laser (7.5 and $15 \mathrm{~J} /$ $\mathrm{cm}^{2}$ ) after 4, 24, and 96 hours after irradiation

\begin{tabular}{|c|c|}
\hline Row & Protein name \\
\hline 1 & GRP58 \\
\hline 2 & Coronin-1A \\
\hline 3 & Fibrinogen b chain \\
\hline 4 & Selenium binding protein 1 \\
\hline 5 & TCP-1-b \\
\hline 6 & Msx-interacting-zinc \\
\hline 7 & finger protein 1 \\
\hline 8 & Ornithine aminotransferase \\
\hline 9 & $\mathrm{LBP} / \mathrm{p} 40$ \\
\hline 10 & Proteosome $26 \mathrm{~S}$ subunit, ATPase \\
\hline 11 & Dynactin subunit 2 \\
\hline 12 & Guanine deaminase \\
\hline 13 & Serine proteinase inhibitor \\
\hline 14 & $\mathrm{NAD}(+)$-specific ICDH \\
\hline 15 & Malate dehydrigenase, cytoplasmic \\
\hline 16 & Proteosome $26 \mathrm{~S}$ subunit \\
\hline 17 & 14-3-3 sigma \\
\hline 18 & Proteosome a5 subunit \\
\hline 19 & $\mathrm{HRF}$ \\
\hline 20 & Rho GDI 2 \\
\hline 21 & Rho GDI 1 \\
\hline 22 & Lactoglutathione lyase \\
\hline 23 & Myosin light chain 1 \\
\hline 24 & ApoA1 \\
\hline 25 & AK 1 \\
\hline 26 & Psmb7 protein \\
\hline 27 & PRDX6 \\
\hline 28 & HSP25 \\
\hline 29 & TIM \\
\hline 30 & $\mathrm{MLC} 2 \mathrm{~F}$ \\
\hline 31 & elF-5A1 \\
\hline
\end{tabular}




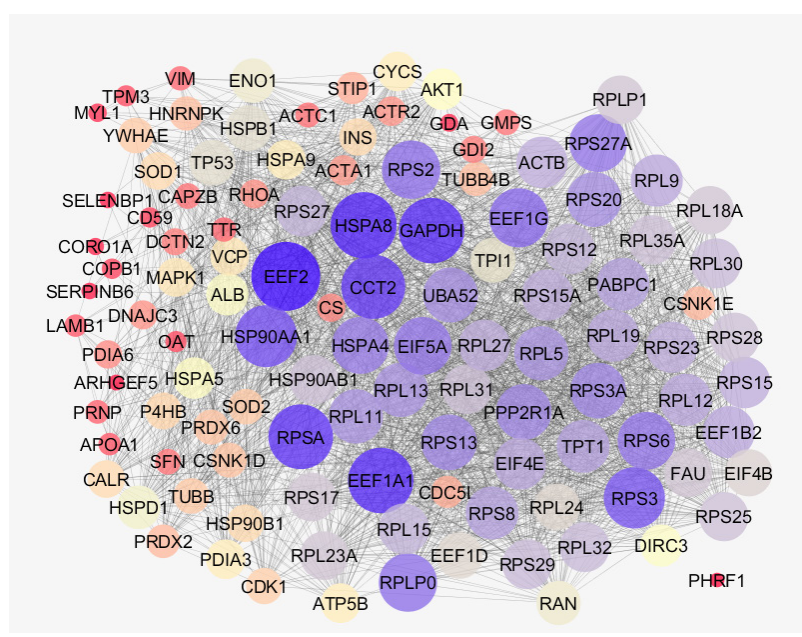

Figure 1. PPI Network Related to Skin of Female Nude Mouse Exposed to Er:YAG Laser $\left(7.5\right.$ and $\left.15 \mathrm{~J} / \mathrm{cm}^{2}\right)$ after 4, 24, and $96 \mathrm{~h}$ After Irradiation. The nodes are layout based on degree value; larger size refer to higher degree value. Confidence score cut off is 0.4

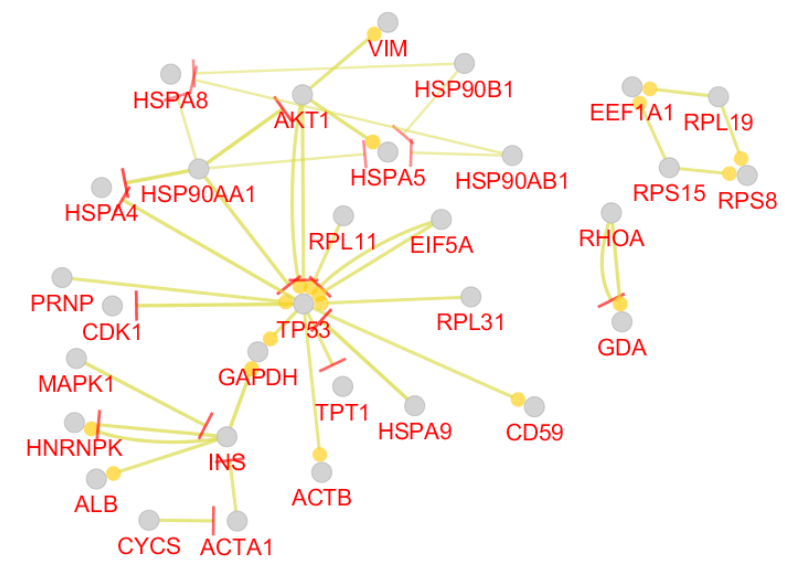

Figure 2. Expression Map of 116 Nodes of Network Related to Skin of Female Nude Mouse Exposed to Er:YAG laser (7.5 and $15 \mathrm{~J} / \mathrm{cm} 2)$ after 4, 24 , and $96 \mathrm{~h}$ After Irradiation. The round and bar tips refer to up-regulation and down-regulation respectively. The isolated proteins are not shown.

seems that RPSA and DCTN2 are the two top proteins based on reaction with the other proteins (Figure 5). Analysis revealed that RPSA reacts mostly with different types of RPL and RPS proteins but DCTN2 is connected to the wide range of proteins types (see Figure 6).

Since the central nodes are the important elements of a network, the top 10 central nodes based on degree values are selected and showed in Table 2. As it is depicted in Table 2, except RPSA the other central proteins are among the 100 added neighbors. Therefore, the top 10 central nodes based on degree values were selected among 16 query proteins (Table 3 ).

\section{Discussion}

Molecular studies could be promising for identification protein biomarkers that are important in a specific

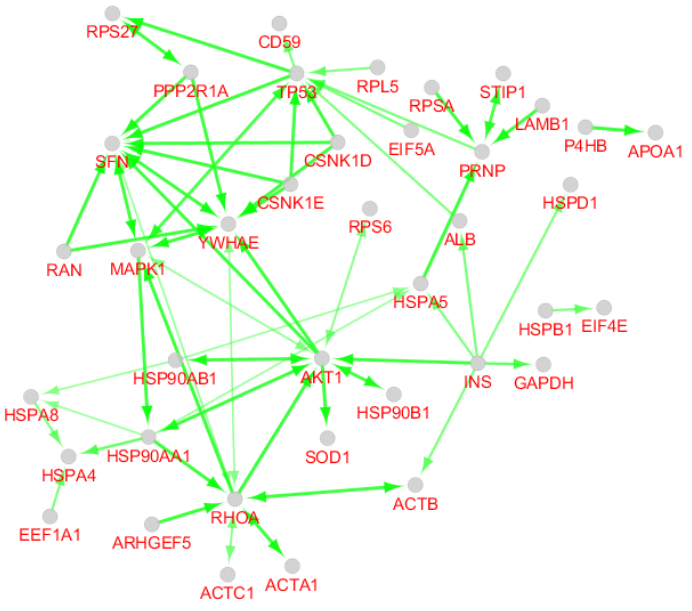

Figure 3. Activation Map of 116 Nodes of Network Related to Skin of Female Nude Mouse Exposed to Er:YAG Laser $\left(7.5\right.$ and $\left.15 \mathrm{~J} / \mathrm{cm}^{2}\right)$ after 4, 24 , and $96 \mathrm{~h}$ After Irradiation. The round and bar tips refer to up-regulation and down-regulation respectively. The isolated proteins are not shown.

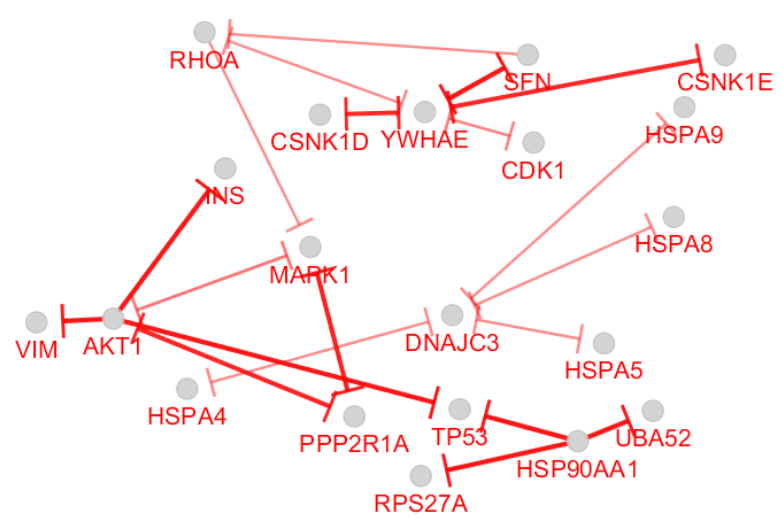

Figure 4. Inhibition Map of 116 Nodes of Network Related to Skin of Female Nude Mouse Exposed to Er:YAG laser $\left(7.5\right.$ and $\left.15 \mathrm{~J} / \mathrm{cm}^{2}\right)$ After 4, 24 , and $96 \mathrm{~h}$ After Irradiation. The round and bar tips refer to up-regulation and down-regulation respectively. The isolated proteins are not shown.

condition such as under special treatments. ${ }^{15}$ These proteins could facilitate the understanding of mechanisms of that applied treatment in an organism. One way to more nourishing the molecular information is to add bioinformatics evaluations. PPI network analysis is a bioinformatics approach that could provide additional data regarding topological features. ${ }^{13}$ One of the novel sources for this purpose is proteomics. ${ }^{7}$ The 31 differentially expressed proteins that were obtained from irradiated mouse model with Er:YAG laser were designated in our study as tabulated in Table 1. A constructed network of these proteins showed that 16 query proteins are recognizable and could be possibly available for further analysis.

Two methods planed to determine crucial proteins among 116 ones: 1 . The key proteins be determine via 


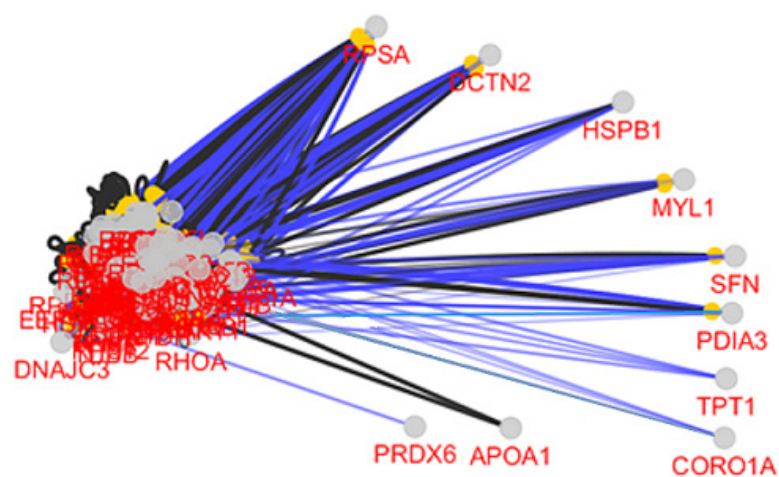

Figure 5. Binding (blue links) and Reaction (black connections) Map of 116 Nodes of Network Related to Skin of Female Nude Mouse Exposed to Er:YAG Laser (7.5 and $15 \mathrm{~J} / \mathrm{cm} 2$ ) After 4, 24, and $96 \mathrm{~h}$ After Irradiation. The query proteins are shown in the right side of network. The round and bar tips refer to up-regulation and down-regulation respectively. The isolated proteins are not shown.

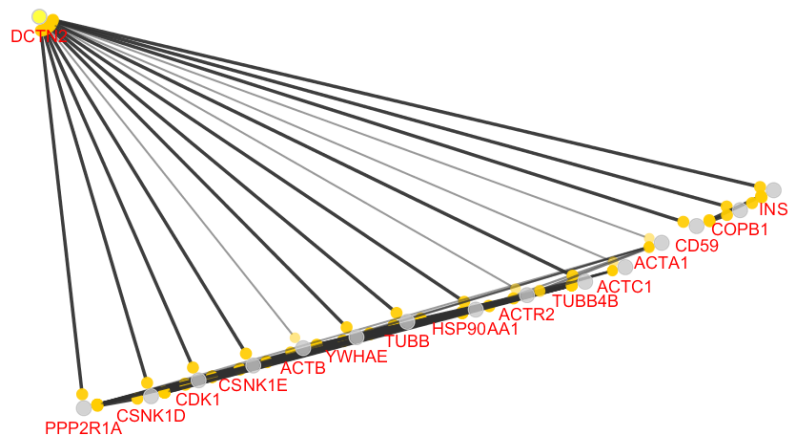

Figure 6. Direct Neighbors Reacting to of Dynactin Subunit 2 (DCTN2). action maps and 2. Selection of the important proteins among central nodes of the constructed PPI network.

Expression map was not informative because the query proteins were not included in this action activity (Figure 2). However down-regulation of TP53 (as one of 100 added proteins) is a significant event. Activation of TP53 in Figure 3 can be interpreted as a compensative mechanism for down regulation of this anti-tumor protein. Activation action provided valuable information about all proteins including query and the added ones (Figure 3). Activation of AKT1, RHOA, and PRNP beside TP53 highlights these four proteins among the added proteins. Activation of query protein SFN by several proteins that all of them are additive proteins, activation of the other query protein APOA1, activation of PRNP by query protein RPSA and activation of RHOA by query protein ARHGEF5 (TIM) are main finding in Figure 3. These findings not only highlight SFN, APOA1, PRSA, and TIM among the query proteins but also expose critical relationship between them and PRNP and RHOA. Inhibition of RHOA by SFN, which is shown in Figure 4, reflects important of both RHOA and FSN in laser irradiation effects on skin.

As it is shown in Figure 5, 10 query proteins interacted (based on binding and reaction actions) with the added proteins in a heterogeneous style. While RPSA has the most connections, PRDX6 only is connected by one link. RPSA is connected mainly to different members of RPL and RPS family. DCTN2 as a query protein is connected to the different types of proteins. Fifteen direct links between DCTN2 and the other proteins is shown in

Table 2. Top 10 Central Nodes of PPI Network Ranked Based on Degree Value

\begin{tabular}{|c|c|c|c|c|}
\hline $\mathbf{R}$ & Display Name & Description & D & BC \\
\hline 1 & EEF2 & Eukaryotic translation elongation factor 2 & 80 & 0.03 \\
\hline 2 & HSPA8 & $\begin{array}{l}\text { Lipopolysaccharide-associated protein 1; Molecular chaperone implicated in a wide variety of cellular processes, } \\
\text { including protection of the proteome from stress, folding and transport of newly synthesized polypeptides. }\end{array}$ & 76 & 0.03 \\
\hline 3 & EEF1A1 & Eukaryotic translation elongation factor 1 alpha 1 ; This protein is involved importantly in Th1 cytokine production. & 75 & 0.02 \\
\hline 4 & GAPDH & $\begin{array}{l}\text { Glyceraldehyde-3-phosphate dehydrogenase; playing a role in glycolysis, nuclear functions and cytoskeleton } \\
\text { activity. }\end{array}$ & 75 & 0.03 \\
\hline 5 & RPSA & $\begin{array}{l}\text { Multidrug resistance-associated protein } \mathrm{MGr} 1-\mathrm{Ag} \text {; Required for the assembly and/or stability of the } 40 \mathrm{~S} \text { ribosomal } \\
\text { subunit. Also functions as a cell surface receptor for laminin. Plays a role in cell adhesion to the basement } \\
\text { membrane and in the consequent activation of signaling transduction pathways. May play a role in cell fate } \\
\text { determination and tissue morphogenesis. }\end{array}$ & 74 & 0.02 \\
\hline 6 & ССТ2 & Chaperonin containing TCP1, subunit 2 (beta); Molecular chaperone. & 73 & 0.03 \\
\hline 7 & HSP90AA1 & Heat shock protein 90kDa alpha (cytosolic), class A member 1; Molecular chaperone. & 70 & 0.03 \\
\hline 8 & RPS3 & $\begin{array}{l}\text { Small ribosomal subunit protein uS3; Involved in translation, endonuclease activity and repair of damaged DNA, } \\
\text { reduction of cellular ROS levels, regulating Binds to and protects TP53/p53 from MDM2-mediated ubiquitination, } \\
\text { regulating microtubule polymerization, apoptosis, Interacts with TRADD following exposure to UV radiation and } \\
\text { induces apoptosis }\end{array}$ & 69 & 0.01 \\
\hline 9 & EEF1G & $\begin{array}{l}\text { Eukaryotic translation elongation factor } 1 \text { gamma; Probably plays a role in anchoring the complex to other } \\
\text { cellular components. }\end{array}$ & 66 & 0.009864 \\
\hline 10 & RPLPO & Large ribosomal subunit protein uL10; Ribosomal protein P0 is the functional equivalent of E. coli protein L10. & 65 & 0.01 \\
\hline
\end{tabular}

Note: D, and BC refer to degree, and betweenness centrality, respectively. 
Table 3. Top 10 Central Nodes (Among Query Proteins) of PPI Network Based on Degree Value

\begin{tabular}{|c|c|c|c|c|c|}
\hline $\mathbf{R}$ & $\begin{array}{l}\text { Display } \\
\text { Name }\end{array}$ & Description & D & BC & Query Term \\
\hline 1 & RPSA & $\begin{array}{l}\text { Multidrug resistance-associated protein } \mathrm{MGr} 1-\mathrm{Ag} \text {; Required for the assembly and/or stability } \\
\text { of the } 40 \mathrm{~S} \text { ribosomal subunit. Also functions as a cell surface receptor for laminin. Plays a } \\
\text { role in cell adhesion to the basement membrane and in the consequent activation of signaling } \\
\text { transduction pathways. May play a role in cell fate determination and tissue morphogenesis. }\end{array}$ & 74 & 0.02 & LBP/p40 \\
\hline 2 & TPT1 & $\begin{array}{l}\text { Tumor protein, translationally-controlled } 1 \text {; Involved in calcium binding and microtubule } \\
\text { stabilization. }\end{array}$ & 57 & 0.01 & $\mathrm{HRF}$ \\
\hline 3 & HSPB1 & $\begin{array}{l}\text { Estrogen-regulated } 24 \text { kDa protein; Small heat shock protein which functions as a molecular } \\
\text { chaperone. }\end{array}$ & 47 & 0.01 & HSP25 \\
\hline 4 & PDIA3 & Protein disulfide isomerase family A member 3. & 38 & 0.01 & GRP58 \\
\hline 5 & PRDX6 & $\begin{array}{l}\text { Acidic calcium-independent phospholipase A2; Thiol-specific peroxidase that catalyzes } \\
\text { the reduction of hydrogen peroxide and organic hydroperoxides to water and alcohols, } \\
\text { respectively. }\end{array}$ & 31 & 0.01 & PRDX6 \\
\hline 6 & DCTN2 & $\begin{array}{l}50 \text { kDa dynein-associated polypeptide; Modulates cytoplasmic dynein binding to an organelle, } \\
\text { and plays a role in prometaphase chromosome alignment and spindle organization during } \\
\text { mitosis. Involved in anchoring microtubules to centrosomes. May play a role in synapse } \\
\text { formation during brain development; Dynactin }\end{array}$ & 19 & 0.01 & Dynactin subunit 2 \\
\hline 7 & SFN & $\begin{array}{l}\text { Epithelial cell marker protein } 1 \text {; Adapter protein implicated in the regulation of a large } \\
\text { spectrum of both general and specialized signaling pathways. May also regulate MDM2 } \\
\text { autoubiquitination and degradation and thereby activate p53/TP53. }\end{array}$ & 17 & 0.01 & 14-3-3 sigma \\
\hline 8 & APOA1 & $\begin{array}{l}\text { Apolipoprotein A-l; Participates in the reverse transport of cholesterol from tissues to the liver } \\
\text { for excretion. }\end{array}$ & 12 & 0.00 & ApoA1 \\
\hline 9 & OAT & Ornithine aminotransferase. & 10 & 0.00 & $\begin{array}{l}\text { Ornithine } \\
\text { aminotransferase }\end{array}$ \\
\hline 10 & MYL1 & Myosin light chain 1/3, skeletal muscle isoform; Regulatory light chain of myosin. & 6 & 0.00 & $\begin{array}{l}\text { Myosin light } \\
\text { chain } 1\end{array}$ \\
\hline
\end{tabular}

$\mathrm{D}$, and $\mathrm{BC}$ refer to degree, and betweenness centrality respectively.

Figure 6. Based on first approach (action plan discovery), TP53, AKT1, RHOA, and PRNP among added proteins and SFN, APOA1, TIM, RPSA, and DCTN2 among the query proteins were introduced as critical proteins.

The centrality exploration of the network was based on two categories, first the whole network and second only the queried proteins. This assessment in Tables 2 and 3 shows that some proteins are particular more fundamental in the network strength. Among them, RPSA (LBP/p40) is common between two tables of the study. This finding denotes this protein as a distinguishable central DEG with high measures of degree and betweenness (hubbottleneck). Three chaperones (rows 2, 6, and 7), three ribosomal proteins (rows 5, 8, and 10), three elongation factors (rows 1, 3, and 9) and GAPDH are highlighted in Table 2. Top rank position of RPSA in Table 3, emphasizes on the importance of ribosomal effeteness of laser irradiation. Effect of laser irradiation on cell proliferation via microtubule stabilization is reflected by dysregulation of TPT1 and DCTN2 in Table 3. HSPB1 and PDIA3 as the third and fourth query central nodes are involved in protein folding and isomerization activities.

Effect of laser irradiation on cell cycle and proliferation is reported by several researchers. ${ }^{16,17}$ It seems that microtubule destabilization is a significant process that is affected by laser irradiation. Down-regulation of TP53 and activation of this anti-tumor protein indicates that control of cell proliferation after laser irradiation is a prominent point regarding using laser therapy. In the other hand laser therapy may be a skin cancer risk factor. However there are many documents about molecular and cellular effects of laser irradiation but there is no sufficient evidence related to correlation between skin cancer and laser therapy. ${ }^{18}$ This point may be related to the weak damages after limited laser irradiation and activation of repair processes. It is discussed that several proteins activate TP53. Prominent role of TP53 in control of cell proliferation, particularly in stressed cells is confirmed by researchers. ${ }^{19}$ AKT1 is the other protein that is involved in cell proliferation and cancer promotion. ${ }^{20}$ According to absence of sufficient evidence for occurrence of cancer after laser therapy, it can probably be concluded that cancer promotion and prevention processes after laser therapy are in balancing.

\section{Conclusion}

It can be concluded that TP53, AKT1, RHOA, PRNP, RPSA, GAPDH, TPT1, DCTN2, HSPB1, and PDIA3 are the critical proteins which play important roles related to exposed skin to laser irradiation. The finding corresponds to balancing between cancer promotion and prevention in laser irradiated skin.

\section{Ethical Considerations}

Not applicable. 


\section{Conflict of Interests}

The authors declare no conflict of interest.

\section{Acknowledgment}

Proteomics Research Center of Shahid Beheshti University of Medical Sciences supports this research.

\section{References}

1. Gladstone GJ. Laser Skin Resurfacing. Oculoplastic Surgery Atlas. Springer; 2018:51-54.

2. Pan TL, Wang PW, Lee WR, et al. Systematic evaluations of skin damage irradiated by an erbium:YAG laser: histopathologic analysis, proteomic profiles, and cellular response. J Dermatol Sci. 2010;58(1):8-18. doi:10.1016/j. jdermsci.2010.02.001

3. Asadzadeh-Aghdaei H, Zamanian Azodi M, Vafaee R, Moravvej Farshi H, Naderi N. SRC and TP53 play critical role in low-grade dysplasia colorectal mucosa transformation into cancer. Gastroenterol Hepatol Bed Bench. 2018;11(Suppl 1):S104-s110.

4. Naderi N, Zamanian Azodi M, Daskar Abkenar E, Shahidi Dadras M, Talaei R. Insulin dysregulation plays a critical role in colon inflammation: a bioinformatics approach. Gastroenterol Hepatol Bed Bench. 2018;11(Suppl 1):S85-s91.

5. Schwanhausser B, Gossen M, Dittmar G, Selbach M. Global analysis of cellular protein translation by pulsed SILAC. Proteomics. 2009;9(1):205-209. doi:10.1002/ pmic. 200800275

6. Wu CH, Huang $\mathrm{H}$, Yeh LS, Barker WC. Protein family classification and functional annotation. Comput Biol Chem. 2003;27(1):37-47.

7. Stelzl U, Worm U, Lalowski M, et al. A human proteinprotein interaction network: a resource for annotating the proteome. Cell. 2005;122(6):957-968. doi:10.1016/j. cell.2005.08.029

8. Rual JF, Venkatesan K, Hao T, et al. Towards a proteomescale map of the human protein-protein interaction network. Nature. 2005;437(7062):1173-1178. doi:10.1038/ nature 04209

9. Rezaei Tavirani M, Bashash D, Tajik Rostami F, et al. Celiac disease microarray analysis based on System Biology Approach. Gastroenterol Hepatol Bed Bench. 2018;11(3):216-224.
10. Shannon P, Markiel A, Ozier O, et al. Cytoscape: a software environment for integrated models of biomolecular interaction networks. Genome Res. 2003;13(11):2498-2504. doi:10.1101/gr.1239303

11. Szklarczyk D, Morris JH, Cook H, et al. The STRING database in 2017: quality-controlled protein-protein association networks, made broadly accessible. Nucleic Acids Res. 2017;45(D1):D362-d368. doi:10.1093/nar/ gkw937

12. Assenov Y, Ramirez F, Schelhorn SE, Lengauer T, Albrecht M. Computing topological parameters of biological networks. Bioinformatics. 2008;24(2):282-284. doi:10.1093/ bioinformatics/btm554

13. Zamanian-Azodi M, Rezaei-Tavirani M. Investigation of health benefits of cocoa in human colorectal cancer cell line, HT-29 through interactome analysis. Gastroenterol Hepatol Bed Bench. 2019;12(1):67-73.

14. Bindea G, Galon J, Mlecnik B. CluePedia Cytoscape plugin: pathway insights using integrated experimental and in silico data. Bioinformatics. 2013;29(5):661-663. doi:10.1093/bioinformatics/btt019

15. Asadzadeh-Aghdaei H, Zamanian Azodi M, Vafaee R, Moravvej Farshi H, Naderi N. SRC and TP53 play critical role in low-grade dysplasia colorectal mucosa transformation into cancer. Gastroenterol Hepatol Bed Bench. 2018;11(Suppl 1):S104-s110.

16. Ganjali M, Seifalian AM, Mozafari M. Effect of Laser Irradiation on Cell Cycle and Mitosis. J Lasers Med Sci. 2018;9(4):249-253. doi:10.15171/jlms.2018.45

17. Kong S, Aoki A, Iwasaki K, et al. Biological effects of Er:YAG laser irradiation on the proliferation of primary human gingival fibroblasts. J Biophotonics. 2018;11(3). doi:10.1002/jbio.201700157

18. Ash C, Town G, Whittall R, Tooze L, Phillips J. Lasers and intense pulsed light (IPL) association with cancerous lesions. Lasers Med Sci. 2017;32(8):1927-1933. doi:10.1007/ s10103-017-2310-y

19. Basset-Seguin N, Moles JP, Mils V, Dereure O, Guilhou JJ. TP53 tumor suppressor gene and skin carcinogenesis. J Invest Dermatol. 1994;103(5 Suppl):102s-106s.

20. Carpten JD, Faber AL, Horn C, et al. A transforming mutation in the pleckstrin homology domain of AKT1 in cancer. Nature. 2007;448(7152):439-444. doi:10.1038/ nature 05933 